Poles, F. C., and Lavertine, J. D. O'D. (1954): Acute Disseminated Histoplasmosis with a Report of a Case Occurring in England, Thorax, 9, 233.

Ponnampalam, J. (1963): Isolation of Histoplasma capsulatum from Soil of a Cave in Central Malaya, Amer. J. trop. Med. Hyg., 12, 775.

Ponnampalam, J. (1964): Histoplasmosis in Malaya, Brit. J. Dis. Chest., 58, 49.

Saliba, A., and BeATTY, O. A. (1962): Treatment of Mycotic Infections: Hydrocortisone in the Control of Amphotericin B Toxicity, Dis. Chest., 41, 214.

Seabury, J. H., and Dascomb, H. E. (1958): Experience with Amphotericin B for the Treatment of Systemic Mycoses, Arch. intern. Med., 102, 960.
Symmers, W. ST. C. (1956): Histoplasmosis Contracted in Britain, Brit. med. J., ii. 786.

Symmers, W. ST. C. (1964): in Proceedings of the Symposium on Medical Mycology, International Academy of Pathology, edited by C. M. Binford and F. K. Mostofi. (Baltimore: Williams and Wilkins) in press.

Tynes, B. S., Utz, J. P., Bennett, J. P., and Alling, D. W. (1963): Reducing Amphotericin B Reactions, Amer. Rev. resp. Dis., 87, 264.

WinN, W. A. (1959): The Use of Amphotericin B in the Treatment of Coccidioidal Disease, Amer. J. Med., 27, 617.

\title{
HYPOGONADISM AND LIFE-LONG ANOSMIA
}

\author{
T. D. R. Hockaday, M.A., B.M., B.Sc. (Oxon), M.R.C.P. (Lond.) \\ Lecturer in Medicine \\ Department of the Regius Professor of Medicine, Radcliffe Infirmary, Oxford
}

THE association of life-long anosmia with gonadal failure in males was first described by Kallman, Schoenfeld and Barrera (1944) and reviewed by Nowakowski and Lenz (1961). The hypogonadism, which may be familial, is thought to be the result of pituitary failure because the urinary excretion of gonadotrophins is absent or greatly reduced, but there has been no indication of failure of secretion of pituitary hormones other than the gonadotrophins. de Morsier (1955) has reviewed the occurrence of agenesis of the olfactory bulbs and tract as found on post-mortem examination, usually of patients who were not known by their relatives to have had a defective sense of smell. Some of these patients were eunuchoid and in a very few the pituitary fossa was small. No evidence of adrenal or thyroid failure was recorded at post-mortem. In one child there was an absence bilaterally of neurones from the area usually occupied by the cells of the lateral tuberal nucleus of the hypothalamus. Damage to this region has been associated in animals with impairment of gonadotrophin production (Mess, 1952; Davidson, Contropoulos and Ganong, 1960).

Two patients are described who illustrate this association of life-long anosmia in males with hypogonadism secondary to pituitary dysfunction.

\section{Case No. 1.}

Mr. H. B. (Radcliffe Infirmary No. 303741) is a 27 year-old man who first attended Out Patients when aged 22 with the complaint of an abnormally highpitched voice. Enquiry revealed many symptoms of reduced testicular function: he did not need to shave, was weak, and had ready "burning" of the skin without tanning on exposure to the sun, a lack of libido and of self-confidence, and only occasional erections. There was no similar abnormality among his family (he has one brother and one sister, both of whom are well, as are his parents). He had had no notable past illness or operation, and had no history of mumps, as far as he remembered. He had had no headaches except occasional ones of the "tension" type. Vision was normal.

He had first complained to his practitioner of similar symptoms when aged 18, and had been treated with testosterone, both as the propionate ester parenterally and as methyl testosterone orally, for a short period. He had noticed changes of maturation on this treatment, with some deepening of his voice, scant growth of facial and pubic hair, and some penile enlargement. His abdominal and upper limb fat had decreased, while his appetite had, if anything, increased.

The results of physical examination were affected by the previous treatment with testosterone but the patient was clearly eunuchoid. Height was 70ins with span 72 and distance from floor to pubis 37ins. There was plentiful subcutaneous fat of feminine distribution over the hips, abdomen, upper parts of the limbs, and in the breasts (where no glandular tissue could be felt). Weight fluctuated between 10 and 11st. Scalp hair was fine in texture with little temporal recession. There was scant facial and pubic hair, and no axillary hair. The skin was pale and thin. The penis and testes were small but not infantile. Muscular strength was normal. The larynx was small but again larger than the usual pre-pubertal size.

Investigation at age 23 showed a normal haemoglobin, blood urea, sugar and electrolytes, while skull X-ray showed a small pituitary fossa with large frontal and maxillary sinuses. The chromosomal pattern of white blood cells was normal. Testicular biopsy revealed almost complete absence of Leydig cells with a reduced number of seminiferous tubules. The basement membrane of these was normal, but spermatogenesis was markedly abnormal, although spermatogonia and primary spermatocytes could be recognised. No spermatozoa were seen and no normal spermatids or secondary spermatocytes were present. The 24-hour urinary excretion of 17-hydroxy-corticoids was $10.2 \mathrm{mg}$. and of $17-$ ketosteroids $4.8 \mathrm{mg}$. Later (when age 28 ) no urinary gonadotrophins could be detected after extraction of the 
urine by Albert's method (1955) and measurement of the ovarian weight of immature female rats after injection of the extract daily for four days. Luteinizinghormone activity was also absent from the urine, as tested by the ovarian cholesterol depletion method (Bell, Mukerji and Loraine, 1964).

At this time he was questioned about his sense of smell. He said he had never appreciated the smell of flowers or perfumes, but could smell smoke. He did not notice fine distinctions in the tastes of foods. On examination, he had complete anosmia, although he appreciated ether or ammonia when sniffed up the nose. He had normal appreciation of the four primary tastes on the tongue.

Further treatment with preparations of testosterone (as a combination of intramuscular testosterone oenanthenate and sublingual methyl testosterone) has again been followed by increase of male secondary sexual characteristics.

\section{Case No. 2.}

Mr. A. D. (Radcliffe Infirmary No. 392061) is a 17year-old patient, detained in a mental hospital as a psychopath. He comes from a disturbed home, and his father is at present in prison.

When age 12 or 13 , failure of descent of the testes and absence of any evidence of maturation led to a course of injections of chorionic gonadotrophin. These produced some deepening of the voice, scanty growth of axillary and pubic hair, some enlargement of the penis and descent of the testes into the scrotum although they remained readily retractile. Once the effect of the injections ceased no further sexual development occurred although growth in height continued. He was referred to hospital because of persistent immaturity of both physique and behaviour, the latter manifested both as petty delinquency and persistent enuresis. He made no complaint of inability to smell scents but when questioned said that he had never been able to appreciate flowers or the odours of food. When eating he appreciated sweet and savoury foods but not the fine distinctions between similar dishes. His father had complete anosmia on testing; the patient said his mother had a normal sense of smell but that his only sib, a brother, had a deficient sense of smell.

On examination he was 67ins tall and weighed 9 st. 8 lbs. Span was $68 \frac{1}{2}$ ins and the distance from the floor to the pubic crest was $34 \frac{1}{2}$ ins. There was very scanty facial hair and a few pubic and axillary hairs of adult type. There was no temporal recession of the scalp hair which was fine in texture. The larynx, penis, and testes were all small but they were larger than those of a child. The prostate could only just be felt rectally.

There was no abnormality in the central nervous system apart from a bilateral anosmia despite normal lower nasal passages. The optic fundi were normal. Investigations; $\mathrm{Hb} 13.2 \mathrm{~g} / 100 \mathrm{ml}$., normal blood film and ESR, and no Barr bodies in neutrophil leucocytes or on a buccal smear. X-ray of the chest and skull were normal, with the pituitary fossa a normal size, while $X$-ray of the hands showed a bone age of 14 to 15 . EEG was normal except for a possibly slight excess of slow activity bilaterally (which might have reflected a normal drowsiness). No gonadotrophins were detectable in a 24-hour urine specimen.

A diagnosis of anosmia and gonadotrophin deficiency was made and he is to receive treatment with testosterone.

\section{Comment}

These cases are reported, first to draw attention to the association between hypogonadism (especially in males) and anosmia, which, though rare, is probably not sought frequently enough for its true incidence to be appreciated and, secondly, to emphasize the importance of this diagnosis for prognosis. Hypogonadism of intracranial origin must always make one fear failure in the future of pituitary secretions other than the gonadotrophic but, when the hypogonadism is allied with anosmia, this progression does not seem to occur. Anosmia is rarely complained of by these patients who in previous instances have been capable cooks or able to detect the odour of cigars overnight (de Morsier, 1955). It is important to establish that the anosmia has been life-long, as trauma can cause anosmia and also lead to pituitary damage with subsequent hypogonadism, or it may cause anosmia in an already eunuchoid subject.

The mechanism of the relationship is unknown. Two suggestions have been made. First, it may be the result of a fault in embryonic development (de Morsier, 1955), for each rudimentary olfactory bulb and tract are in line with the hypothalamus, particularly its paramedian structures, which showed hypoplasia in various degrees in three cases reported by Gauthier (1960), although in none was there absence of the lateral tuberal nuclei. Secondly, it has been suggested that there is an important and direct neural connection between the olfactory nuclei and the region of the lateral tuberal nuclei, but it has never been established, even in animals (Lundberg, 1960; Nauta, 1961), that this is precise and exclusive enough for one to expect congenital anosmia to be associated with failure of the development in this region.

The variability of the hypothalamic defects in Gauthier's patients (1960), together with occurrence in these patients of a variety of other developmental defects (de Morsier, 1955), support the former alternative, and the title proposed by de Morsier of a "paramedian olfacto-ethmoido-hypothalamic dysraphia."

I wish to thank Professor Sir George Pickering, F.R.S., for permission to describe these patients, and $\mathrm{Mr}$. $\mathrm{G}$. Higgins of the Nuffield Department of Biochemistry for the steroid estimations (Case 1).

\section{REFERENCES}

Albert, A. (1955): Procedure for Routine Clinical Determination of Urinary Gonadotrophin, Proc. Mayo Clin., 30, 552.

Bell, E. T., MukerJi, S., and Loraine, J. A. (1964): A New Bioassay Method for Luteinizing Hormone Depending on the Depletion of Rat Ovarian Cholesterol, J. Endocr., 28, 321.

Davidson, J. M. Contropoulos, A. N., and Ganong, W. F. (1960): Decreased Gonadotrophic Hormone Content of the Anterior Pituitary Gland in Dogs with Hypothalamic Lesions, Endocrinology, 66, 735.

GAUTHIER, G. (1960): La Dysplasie Olfacto-génitale, Acta neuroveg. (Wien), 21, 345.

Kallman, F. J., Schoenfeld, W. A., and Barrera, S. E. (1944): Genetic Aspects of Primary Eunuchnoidism, Amer. J. ment. Defic., 48, 203.

LundBerg, P. O. (1960): Cortico-hypothalamic Connections in the Rabbit, Acta physiol. scand., 49, Suppl. 171.

MESS, B. (1952): Influence of Hypothalamic Injury on Spermatogenesis in Albino Rats, Acta morph. Acad. Sci. hung., 2, 275. 
de Morsier, D. (1955): Etudes sur les Dysraphies Crânioencéphaliques. 1. Agénésie des Lobes Olfactifs (Télencéphaloschisis Latéral) et des Commissures Calleuse et Anterieure (Télencéphaloschisis Mediàn). Schweiz. Arch. Neurol. Psychiat., 74, 309.
Nauta, W. H. J. (1961): Fibre Degeneration following Lesions of the Amygdaloid Complex in the Monkey, J. Anat. (Lond.), 95, 515.

NowaKowSKI, H. and LENZ, W. (1961): Genetic $C$ Aspects in Male Hypogonadism, Recent Progr. Hormone Res., 17, 53.

\title{
A PSEUDOTUMOUR OF THE HAND
}

\section{(An abnormal flexor digitorum sublimis)}

\author{
D. Barrie CaSe, M.B., F.R.C.S. \\ Orthopaedic Registrar, \\ Alder Hey Children's Hospital, Liverpool
}

THs is an account of a previously unreported variety of "tumour" of the hand.

\section{Case Report}

A girl, aged sixteen years, presented with a swelling in the right palm and complained of some pain in the wrist. She gave a history of having sustained a blow on the hand with a tennis ball four years previously and dated her symptoms from that time, but stated that the pain and swelling had subsided in the interim period and had not troubled her until she had started work, a iob which, at some time, involved screwing bottle tops. On examination there was a "tumour" extending proximally about one and a half inches from the region of the second metacarpal head and lying medial to the thenar eminence. Its maximum breadth was threequarters of an inch. The "tumour" appeared to lie deep to the palmar aponeurosis and there was a dusky hue associated with it. It was of smooth outline and texture and was not adherent to skin: the emptying sign of a haemangioma was not obtainable. There was a suggestion of contracture of the index tendon when the finger was forced passively into extension. Exploration was advised upon a diagnosis of a tendon sheath tumour.

Operation. Through a palmar crease incision, the tendon of the flexor digitorum sublimis (N.T. superficialis) to the index finger was found to be interrupted by a small fusiform muscle belly, the tendon ending at the proximal pole of the normal-looking muscle and commencing again at its distal pole. (see Fig. 1). The muscle twitched when it was pinched with forceps but the nerve supply was not isolated: it did not appear to arise from the digital branches of the median nerve to the first and second web spaces. A vascular pedicle entered the deep (dorsal) surface of the muscle from the depth of the palm, but nerve fibres were not obvious in this.

A superficial portion of the muscle was shaved off to decrease the bulk of the swelling and the skin was closed.

There was no similar "tumour" in the left palm.

\section{Discussion}

No mention of this anomaly has been found in the text books, anatomical or surgical, of the Englishspeaking world.

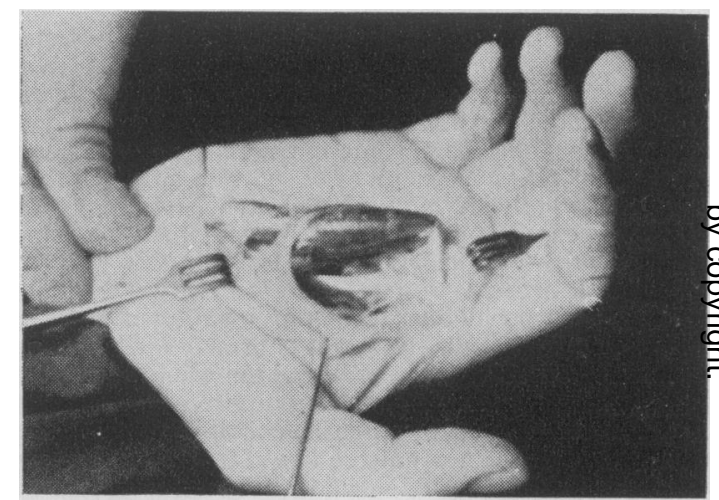

FIG. 1.-View from radial aspect showing the muscle belly and tendon which have been lifted up - the tendon of flexor digitorum profundus to the index finger and its lumbrical muscle are shown deep.

Gaisford (1960) classified tumours of the hand into three groups, benign, malignant and pseudotumours. This condition would, without doubt, fall into the third category. Gaisford does not include it in his list of pseudotumours nor is this anomaly reported by other authors. (Bunnell, 1956; Byrne, 1954; Clarkson and Pelly, 1962; Howard, 1951; Mason, 1937; Pack, 1939; Posch, 1956; Stack, 1960, 1964). Clearly it must be included in the differential diagnosis of hand tumours.

The flexor digitorum sublimis is a mammalian innovation, having several morphological components. The muscle belly arises by cleavage from the intermediate portion of the superficial brachio-antebrachial muscle mass. The proximal portions of the tendons are either split off from the profundus tendons, or are perhaps formed de novo by local condensations of mesenchyme. The distal portions of the tendons, including their insertions, are thought to develop from the primitive (reptilian) superficial short digital flexors, a view which may have some bearing on this case. 